\title{
EXOMORFOLOGÍA Y ANATOMÍA DE LA AGALLA BIVALVA FOLIAR INDUCIDA POR RHOPALOMYIa SP. (INSECTA, Diptera, CeCIDOMYIIDAE) EN Prosopis CALDENIA (FABACEAE)
}

\author{
BÁRBARA MARIANA CORRÓ MOLAS ${ }^{1}$, JUAN JOSÉ MARTÍNEZ ${ }^{1,2}$, SANTIAGO \\ NACARATTI' ${ }^{1}$, JUAN JOSÉ ARRESE1 ${ }^{1}$, NICOLÁS TESTA ${ }^{1}$ y MAGALÍ NEREA ÁLVAREZ1
}

\begin{abstract}
Summary: External morphology and anatomy of the foliar bivalve gall induced by Rhopalomyia sp. (Diptera: Cecidomyiidae) on Prosopis caldenia (Fabaceae). An undescribed species of Rhopalomyia (Diptera: Cecidomyiidae) induces galls on the leaves of Prosopis caldenia. The aims of this work are: to describe the external morphology of these galls, to differentiate its developmental stages and to describe the modifications induced on the foliar tissues. Normal and galled leaves were collected between February 2014 and November 2015 in a fragment of $P$. caldenia forest located in a peri-urban area in Santa Rosa, La Pampa, Argentina. The external morphology of the gall was studied by dissecting some galls under the stereomicroscope. Gall tissues were examined in temporal and permanent microscopic slides containing free hand and microtome sections respectively. The gall is composed of two coalescent adjacent leaflets, originating a bivalve and unilocular structure, with bilateral symmetry, containing the larva of the inducer. The gall presents a continuous layer of nutritive tissue covering the inner wall of the larval chamber, and also has protective and support tissues derived from epidermal and parenchymatic cells modified as sclereids. The tissue that suffers the most important modification is the foliar epidermis.
\end{abstract}

Key words: Leaf galls, Cecidomyiidae, Prosopis, Rhopalomyia.

\begin{abstract}
Resumen: En las hojas de caldén, Prosopis caldenia (Fabaceae), una especie aún no descripta de Rhopalomyia (Diptera: Cecidomyiidae) desarrolla agallas. Los objetivos de este estudio fueron describir exomorfológicamente la agalla inducida en los folíolos de la hoja de $P$. caldenia, diferenciar los estadios de desarrollo de la agalla y describir las modificaciones inducidas en los tejidos foliares agallados. Se colectaron hojas normales y con agallas entre febrero 2014 y noviembre 2015 en un fragmento de bosque de caldén ubicado en el área periurbana de Santa Rosa, La Pampa, Argentina. La morfología externa de la agalla se examinó mediante disección bajo microscopio estereoscópico. El examen de los tejidos foliares se realizó mediante preparados microscópicos temporarios y permanentes de cortes a mano alzada y con micrótomo respectivamente. La agalla está formada por la coalescencia parcial de dos folíolos contiguos acoplados generando una agalla bivalva con simetría bilateral, unicameral y conteniendo una larva del inductor. En la agalla se desarrolla un tejido nutritivo continuo que tapiza la superficie interna de la cámara larval y tejidos con función protectora y de sostén formados por células epidérmicas y parenquimáticas modificadas en esclereidas. La epidermis foliar es el tejido que experimenta los cambios más variados y profundos.
\end{abstract}

Palabras clave: Agallas foliares, Cecidomyiidae, Prosopis, Rhopalomyia.

\section{INTRODUCCIÓN}

Uno de los conceptos más recientes de agalla entomógena considera que la agalla es una expresión

\footnotetext{
1 Universidad Nacional de La Pampa, Avenida Uruguay 151, CP 6300, Santa Rosa, La Pampa.

2 CONICET
}

morfológica de una serie de adaptaciones de la planta hospedera para contener al insecto inductor (Raman, 2007). El insecto inductor genera una perturbación o desviación en el patrón de crecimiento y altera el proceso de diferenciación en la planta hospedera resultando un órgano neoformado en una estructura simétrica y generado a partir de un nuevo patrón ordenado y repetitivo de división y diferenciación celular, la agalla (Raman, 2007; Isaias et al., 2014) 
Generalmente, la agalla representa un morfotipo particular, la forma, tamaño y estructura son específicos para la especie inductora. En este sentido y acorde al concepto de fenotipo extendido de Dawkins (1982), algunos autores consideran a la agalla como parte del fenotipo extendido del inductor (Stone \& Cook, 1998; Bourg \& Hanson, 2014). La agalla constituye un microambiente que provee de protección y nutrición al insecto inductor (Price et al., 1987) y en muchos casos soporta una comunidad de organismos parasitoides e inquilinos representando un microhábitat para una comunidad discreta de organismos especializados (Ferraz \& Monteiro, 2003; Stone \& Schönrogge, 2003; Raman, 2007; Maia, 2012).

En general, los insectos gallígenos son específicos de la planta hospedadora y del órgano atacado (Dreger-Jaufret \& Shorthouse, 1992) y particularmente en la fauna de cecidómidos de Brasil, Carneiro et al. (2009) registraron más del 90 $\%$ de especies monófagas. Se han registrado agallas en todos los órganos vegetales y las hojas son los órganos más afectados y con mayor diversidad de morfotipos de agallas (Dreger-Jaufret \& Shorthouse, 1992). El proceso de formación y las características estructurales de la agalla están principalmente relacionados a la especie inductora más que al órgano afectado, a la especie hospedadora y a los factores ambientales (Dreger-Jaufret \& Shorthouse, 1992; Kraus, 1997; Abrahamson et al., 1998; Stone \& Cook, 1998; Dorchin et al., 2003; Stone \& Schönrogge, 2003; Méndes de Sá et al., 2009). Las agallas más complejas estructuralmente muestran una diferenciación de capas de tejidos vegetales especializados para la protección y para la nutrición del inductor (Kraus, 1997; Stone \& Schönrogge, 2003). Entre las agallas más complejas se destacan las inducidas por Himenópteros y por algunas especies de Cecidomyiidae (Diptera) (DregerJaufret \& Shorthouse, 1992; Stone \& Cook, 1998; Marini-Fillho \& Fernandes, 2012). En particular, las agallas de cecidómidos desarrollan zonas de tejidos especializados bien definidas estructuralmente tales como una zona interna de células nutritivas que limita la cámara larval, una zona de protección frecuentemente formada por células lignificadas y en algunos casos un tejido de reserva (Rohfritsch, 1999; Oliveira et al., 2010; Oliveira \& Isaias, 2010). Estudios recientes muestran que hay variaciones citológicas e histoquímicas entre estas zonas especializadas y entre los estados de maduración de las agallas (Oliveira et al., 2010). La continua actividad de alimentación del cecidómido gallícola parece ser el estímulo para la formación estructural de la agalla y para mantener las variaciones histoquímicas en los tejidos afectados (Cook, 1904; Price et al., 1987; Oliveira et al., 2010).

En la Argentina se han registrado agallas de Cecidomyiidae en especies de Prosopis (Kieffer \& Jörgensen, 1910; Gagné, 1994; Carabajal \& Fiorentino, 2006). En particular, en Prosopis caldenia Burkart, Tetradiplosis panghitruz Martínez induce agallas sobre tallos jóvenes y Tetradiplosis rayen Martínez induce agallas en el raquis de las inflorescencias (Martínez, 2009; Martínez et al., 2013; Corró Molas et al., 2014).

Este trabajo es parte de un estudio sobre los aspectos biológicos y la diversidad de las agallas desarrolladas en especies arbóreas y arbustivas del caldenal. Particularmente en el caldén, hasta el momento se han encontrado 12 morfotipos de agallas entomógenas y un morfotipo inducido por ácaros (Martínez \& Corró Molas, 2016). No obstante, hasta el presente sólo se ha descripto la mofo-anatomía de la agalla inducida por el cecidómido Tetradiplosis panghitruz en los tallos de P. caldenia (Corró Molas et al., 2014).

Los objetivos de este estudio son describir exomorfológicamente la agalla inducida en los folíolos de la hoja de P. caldenia, diferenciar los estadios de desarrollo de la agalla y describir las modificaciones inducidas en los tejidos foliares agallados.

\section{Material y Método}

El estudio se llevó a cabo en un fragmento de bosque de caldén ubicado en el área periurbana de Santa Rosa, La Pampa, Argentina. Se colectaron de árboles de $P$. caldenia hojas adultas sin agallas en febrero de 2014, hojas jóvenes en octubre de 2014 y mensualmente hojas con agallas de octubre de 2014 a noviembre de 2015. El material colectado fue fijado con FAA (alcohol $96^{\circ}$ - agua destilada - formol - ácido acético glacial en proporción 10:7:2:1) y posteriormente conservado en alcohol $70^{\circ}$ (D'Ambrogio de Argüeso, 1986).

Para analizar las modificaciones producidas por el desarrollo de la agalla, se estudiaron las 


\section{B. M. Corró Molas et al. - Agallas foliares en Prosopis caldenia}

características anatómicas del folíolo normal a partir de cortes transversales con micrótomo de folíolos $(\mathrm{N}=11)$ de distintas hojas adultas. Se registraron los valores del espesor del mesófilo en los dos hemilimbos y el espesor de la lámina a nivel de la vena media utilizando fotografías digitales de los cortes microscópicos. Se analizó la venación según los trabajos de Hickey (1974) y Ash et al. (1999) de folíolos $(\mathrm{N}=20)$ de distintas hojas diafanizados en solución acuosa de hipoclorito de sodio (D'Ambrogio de Argüeso, 1986). Para observar la epidermis en vista superficial, se realizó la técnica de peeling sobre el material diafanizado dado que la epidermis se desprende fácilmente de los folíolos diafanizados (D'Ambrogio de Argüeso, 1986). Para teñir el material diafanizado se utilizaron dos colorantes en solución acuosa, la safranina para observar la venación y el azul de toluidina, para observar la venación y la epidermis (D'Ambrogio de Argüeso, 1986).

En este estudio, para diferenciar las agalla en crecimiento, madura y senescente se consideraron el estado de desarrollo del inductor y las cuatro fases básicas de desarrollo de las agallas propuesta por Rohfritsch (1992). No fue posible identificar el momento y sitio de oviposición y el inicio de la inducción de la agalla, por lo cual la primera fase del desarrollo, la agalla incipiente aún no se ha descripto. La segunda fase de la agalla, de crecimiento y diferenciación fue identificada como la agalla en desarrollo conteniendo la larva II, la fase de maduración fue identificada como la agalla madura conteniendo la larva III y la pupa y, la cuarta fase fue la agalla senescente conteniendo la pupa madura o bien la exuvia como resultado de la emergencia del adulto. Para observar el estado de desarrollo del inductor (larva y pupa) en el interior de la agalla y describir la exomorfología de las agallas en desarrollo $(\mathrm{N}=10)$, maduras $(\mathrm{N}=20)$ y senescentes $(\mathrm{N}=5)$ se realizó la disección de las agallas bajo microscopio estereoscópico.

La anatomía de las agallas se estudió mediante cortes con micrótomo transversales $(\mathrm{N}=6)$ y longitudinales $(\mathrm{N}=2)$ de agallas completamente desarrolladas y cortes transversales a mano alzada de agallas en desarrollo $(\mathrm{N}=10)$ y de agallas completamente formadas, maduras $(\mathrm{N}=20)$ y senescentes $(\mathrm{N}=5)$. Se obtuvo una aproximación del espesor de la lámina de 6 folíolos agallados cortados transversalmente con micrótomo. Para observar la venación se diafanizaron con hipoclorito de sodio en solución acuosa folíolos agallados $(\mathrm{N}=10)$. La epidermis de los folíolos agallados se examinó en vista superficial del material diafanizado. No fue posible aplicar la técnica de peeling porque los folíolos agallados se quiebran cuando se intenta extraer la epidermis.

En los preparados temporarios de los cortes a mano alzada de las agallas se utilizaron los colorantes azul de toluidina y safranina en solución acuosa. Los preparados permanentes se llevaron a cabo en el Laboratorio de Morfología Vegetal de la Facultad de Agronomía y Veterinaria de la Universidad Nacional de Río Cuarto (Córdoba, Argentina). Se prosiguió acorde a la técnica de deshidratación con una serie ascendente de alcoholes etílicos y a la técnica inclusión en parafina y tinción con safranina-verde rápido propuesta por D'Ambrogio de Argüeso (1986) utilizando Pathoclear ${ }^{\circledR}$ Plus (Biopack $\left.{ }^{\circledR}\right)$ como sustituto del solvente xileno. Los cortes con micrótomo de folíolos normales y agallados fueron de $12 \mu \mathrm{m}$ de espesor y se utilizó un micrótomo Microm HM 310-tipo rotativo.

En los folíolos normales se observaron idioblastos con contenido coloidal y granulado, por lo cual se realizó la prueba histoquímica con cloruro férrico sobre un extracto acuoso de folíolos frescos para corroborar la presencia de taninos.

Las fotografías fueron obtenidas con cámara digital Sony 20,4 MP.

Los insectos inductores fueron identificados siguiendo las claves propuestas por Gagné (1994) y Maia (2014).

\section{Resultados}

Anatomía foliar de Prosopis caldenia sin agallas

La hoja de $P$. caldenia es bipinnada y uni/ bi y tetrayugada. Los folíolos son peciolados, presentan la lámina oblonga, margen entero, ápice acuminado a redondeado, base levemente cordada y asimétrica (Figura 1A). La venación del folíolo es pinnada, la vena primaria es muy gruesa, tamaño masivo acorde a la clasificación de Hickey (1974) y de recorrido derecho hasta el ápice del folíolo donde se ramifica antes de llegar al margen y finaliza en elementos traqueales. La venación secundaria es camptódroma broquidódroma, las venas secundarias son gruesas, se ramifican y se 
Bol. Soc. Argent. Bot. 52 (3) 2017

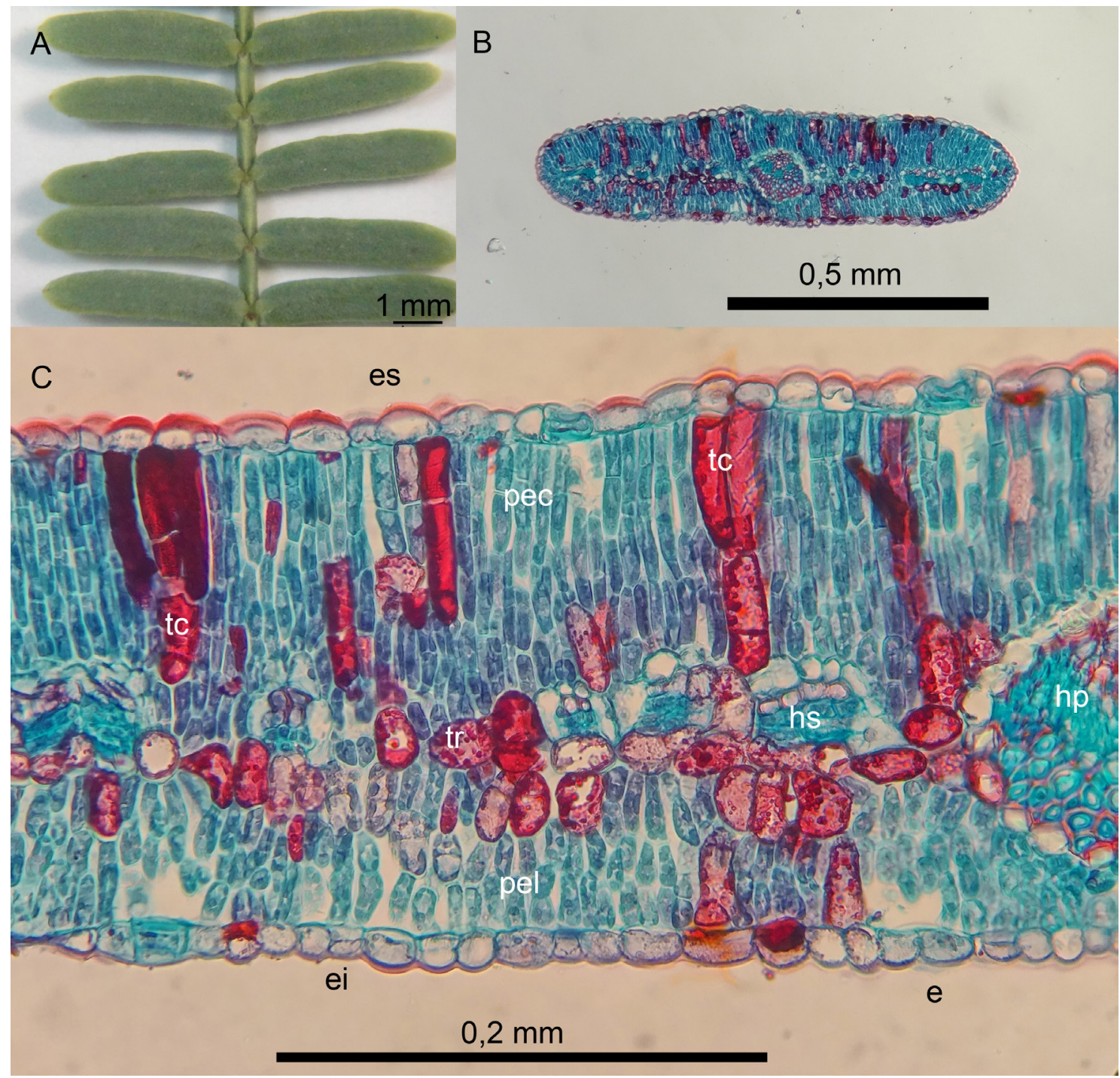

Fig. 1. Hoja normal. A. Raquis secundario y folíolos. B-C. Corte transversal de la lámina del folíolo normal. e: estoma, ei: epidermis inferior, es: epidermis superior, hs: haz vascular secundario, hp: haz vascular primario, pec: parénquima en empalizada compacto, pel: parénquima en empalizada laxo, tc: célula columnar con tanino coloidal, tr: célula redondeada con tanino granulado.

enlazan antes de llegar al margen de la lámina, formando la venación marginal ojalada. El ángulo de divergencia de las venas secundarias varía de agudo a casi recto y a cada lado de la vena principal, se observan de 4 a 7 venas secundarias. La venación terciaria es reticulada, las vénulas terminan en elementos traqueales. Los folíolos presentan tricomas pluricelulares glandulares en la base del peciolulo y tricomas unicelulares filiformes en el peciolulo y en la lámina, generalmente en el margen. En vista superficial, las células epidérmicas tienen contorno rectilíneo.

En el transcorte de la lámina del folíolo maduro (Figura 1B, C) se observan la epidermis adaxial 


\section{B. M. Corró Molas et al. - Agallas foliares en Prosopis caldenia}

y abaxial uniestratas, los estomas presentes en ambas epidermis y tricomas eglandulares, simples, unicelulares. El mesófilo está diferenciado en un parénquima en empalizada, denso hacia la cara adaxial y laxo hacia la cara abaxial. El parénquima en empalizada adaxial presenta células fotosintéticas columnares dispuestas en promedio, en cuatro estratos y abundantes idioblastos con tanino coloidal y granulado. Las células con taninos son columnares y de mayor tamaño que las células fotosintéticas. El parénquima en empalizada abaxial presenta células dispuestas en promedio, en tres estratos y escasos idioblastos redondeados con tanino granulado. Entre ambos parénquimas en empalizada se observa un parénquima esponjoso formado por grandes células redondeadas con tanino granulado. El espesor promedio del mesófilo en ambos hemilimbos es $0,19 \mathrm{~mm}(\mathrm{~N}=11$, ds $=$ $0,2)$ y el espesor promedio de la lámina a nivel de la vena media $0,23 \mathrm{~mm}(\mathrm{~N}=11, \mathrm{ds}=0,02)$. Los haces vasculares son colaterales, el haz vascular principal presenta hacia la superficie abaxial, un paquete de fibras gelatinosas en forma de media luna y los haces vasculares de segundo orden presentan vaina parenquimática. Se encuentran cristales prismáticos alrededor de las venas y drusas en el mesófilo.

\section{Especie inductora}

Las agallas estudiadas en el presente trabajo son desarrolladas en los folíolos de las hojas de Prosopis caldenia e inducidos por una especie aún no descripta de Rhopalomyia, Diptera, Cecidomyiidae. El ciclo de vida de esta especie de Rhopalomyia comprende los estados de huevo, larva (larva I, II y III), pupa y adulto. Los estados juveniles, larva y pupa, crecen y maduran en el interior de la agalla. El adulto abandona la agalla separando los folíolos agallados, la agalla no presenta un orifico de salida del adulto.

\section{Desarrollo de la agalla}

El examen de las yemas y primordios foliares no reveló la presencia de huevos del inductor. Hasta el presente, se desconoce el sitio específico de la oviposición y el inicio de la inducción de la agalla.

En la hoja juvenil y con los folíolos plegados, las agallas se encuentran en las primeras fases del desarrollo, son de tamaño similar al de los folíolos juveniles normales y si bien son visibles a simple vista, con frecuencia es difícil distinguirlas (Figura
2 A). La cámara larval se encuentra claramente delimitada sin embargo, es poco evidente externamente porque es relativamente plana. En este estado inicial de desarrollo, las agallas son pequeñas, presentan una coloración que varía de verde a rojizo y en su interior contiene a la larva inmadura del inductor (Figura 2 B). En las hojas maduras, las agallas completaron su desarrollo y son claramente visibles a simple vista (Figura 2 C-E).

En el área de estudio, la brotación de los caldenes comenzó en septiembre de 2014, a principios de la primavera y, la caída de las hojas a mediados del otoño de 2015. En ese lapso, se desarrollaron por lo menos tres generaciones de agallas superpuestas, se colectaron los distintos estados de desarrollo juveniles del inductor y la emergencia de los adultos ocurrió en tres momentos de la temporada.

\section{Exomorfología de la agalla}

La agalla se forma por la combinación y coalescencia parcial de dos folíolos contiguos (Figura 2 C, D). Cada folíolo constituye una valva de modo que la agalla es una estructura bivalva con simetría bilateral. Los folíolos agallados son contiguos en el raquis secundario, es decir, están ubicados en el mismo lado sobre el raquis. De esta manera, en la agalla se distinguen un folíolo basal, que da lugar a la valva inferior de la agalla $\mathrm{y}$ un folíolo distal que da lugar a la valva superior (Figura $2 \mathrm{C}, \mathrm{D}$ ). Una parte o toda la lámina de ambos folíolos agallados se unen por los márgenes para delimitar una única cavidad, la cámara larval, que alberga una larva del insecto inductor (Figura 2 D). Externamente la cámara larval es oval y se distingue claramente en la agalla que completó su desarrollo por el aspecto globoso. La zona de unión de los folíolos es visible a simple vista. La agalla se ubica adpresa sobre el raquis secundario y en posición vertical. Es frecuente que en una hoja, se desarrollen varias agallas próximas resultando en un conjunto de agallas dispuestas en serie sobre el raquis secundario (Figura $2 \mathrm{E}$ ). Las agallas completamente desarrolladas se observan en la hoja adulta y en general, son de color verde. La salida del adulto ocurre por la dehiscencia de la agalla, las valvas se separan en el extremo distal de la agalla por la zona de unión (Figura 2 F) Es frecuente, encontrar en el campo la exuvia de la pupa que permanece entre las valvas abiertas de la agalla. 
Bol. Soc. Argent. Bot. 52 (3) 2017

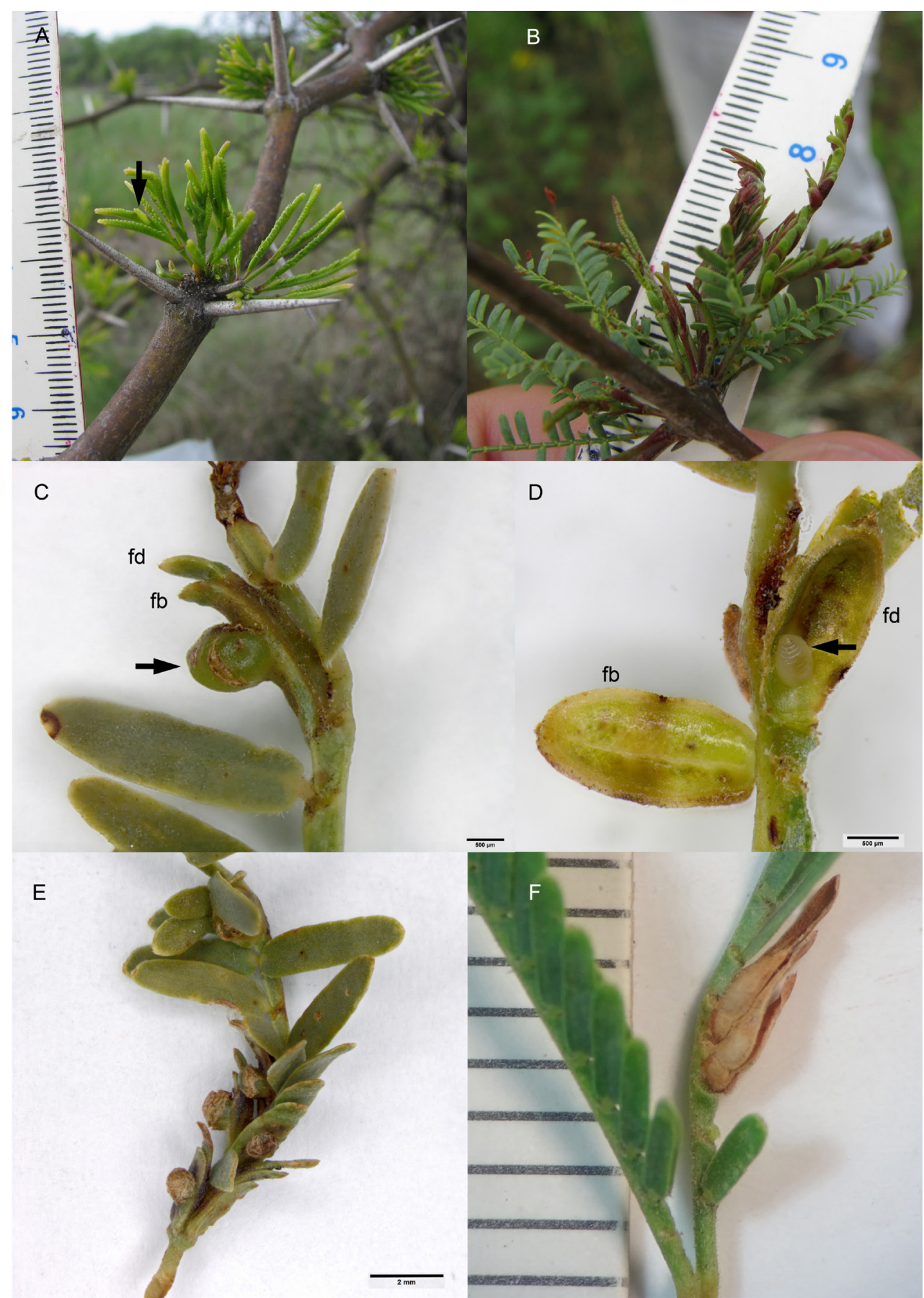

Fig. 2. Agallas. A. Agallas incipientes (flecha) en hojas jóvenes con los folíolos plegados, B. Agallas incipientes rojizas en hojas jóvenes con los folíolos desplegados, C. Agalla madura vista lateral, con excrecencia ovoide (flecha) en el folíolo basal o inferior. D. Agalla con la larva (flecha) en la cámara larval, se retiró el folíolo basal. E. Agallas dispuestas en serie sobre el raquis secundario. F. Agallas senescentes abiertas por la emergencia del insecto adulto. fb: folíolo agallado basal, fd: folíolo agallado distal. 


\section{B. M. Corró Molas et al. - Agallas foliares en Prosopis caldenia}

En este estado, la agalla se torna de color marrón y puede permanecer un tiempo unida a la hoja. El raquis secundario que sostiene una o más agallas, puede permanecer recto o sufrir una inflexión.

En algunas agallas, sobre la superficie adaxial del folíolo inferior se desarrolla una excrecencia a modo de protuberancia, con apariencia globular y forma redondeada a ovalada (Figura $2 \mathrm{C}, \mathrm{E}$ ). La coloración, la superficie externa y la consistencia de esta protuberancia varían según el desarrollo de la agalla. En las agallas en formación y maduras, la coloración varía entre verde y rojiza, el aspecto superficial es liso y la consistencia es firme. En la agalla senescente, pronta a abrirse o abierta, la protuberancia es de color ocre claro con la superficie externa agrietada.

\section{Anatomía de la agalla}

Los folíolos juveniles en las primeras fases del desarrollo de la agalla, están aplicados uno sobre otro y débilmente unidos. La vena principal en cada folíolo juvenil agallado se extiende desde la base hasta el ápice de la lámina del folíolo y en el transcorte se observan los tejidos vasculares y el casquete de fibras reducido. Las venas de segundo y tercer orden están en general y en comparación al folíolo normal, poco desarrolladas en número, extensión y tejidos vasculares. La cámara larval está claramente delimitada y las células epidérmicas que la tapizan forman una epidermis uniforme sin estomas, las paredes celulares son finas y en vista superficial, presentan contornos rectilíneos. Por otra parte, las células epidérmicas ubicadas a lo largo de todo el contorno de la cámara, tienen forma irregular, se proyectan hacia el exterior en forma aguzada y presentan la pared celular engrosada y lignificada. El mesófilo en el folíolo juvenil agallado y a nivel de la cámara larval, presenta las células del parénquima más alejado de la superficie interna de la cámara larval, con forma columnar y dispuestas en empalizada, y las células del parénquima ubicado próximo a la cámara larval presentan forma redondeada y están dispuestas en forma similar a un parénquima esponjoso con escasos meatos.

La agalla madura, completamente desarrollada, se encuentra en la hoja adulta y los folíolos que la conforman están firmemente acoplados delimitando la cámara de sección oval (Figura 3 A, B). Las células epidérmicas de la zona de contacto entre los folíolos agallados, que ya están modificadas en las primeras fases de desarrollo de la agalla, en la agalla madura están transformadas en esclereidas con paredes celulares tangenciales externas y radiales muy gruesas y las paredes tangenciales internas delgadas. La forma celular varía desde células triangulares con extremos puntiagudos a células aproximadamente rectangulares con los extremos redondeados y salientes (Figura $3 \mathrm{C}-\mathrm{F}$ ). Las células de ambos folíolos, en la zona de contacto están entrelazadas o encastradas de manera que la cámara permanece cerrada (Figura $3 \mathrm{~A}, \mathrm{~B}$ )

En el transcorte de ambos folíolos agallados y a nivel de la cámara larval, se observan hacia la superficie interna de la cámara, 3-4 capas compactas de células con pared celular delgada, citoplasma denso, núcleo grande y vacuolas pequeñas o ausentes. La forma celular varía desde triangular, cuadrangular a oval. Estas células están en contacto directo con la larva y se disponen cubriendo en forma continua toda la superficie interna de la pared de la cámara larval. Las características celulares mencionadas y su posición son acordes a las descripciones de las células que forman el tejido nutritivo desarrollado en las agallas de cecidómidos (Bronner, 1992). Este tejido nutritivo en la agalla bivalva corresponde a la epidermis modificada y representa aproximadamente más de la mitad del espesor de la lámina (Figura 3 A-D). En el folíolo inferior, corresponde a la epidermis adaxial y en el folíolo superior, a la epidermis abaxial. En este tejido nutritivo ocurre aumento del tamaño celular (hipertrofia) y en los estratos más internos del tejido, se observa proliferación celular (hiplerplasia) (Figura 3 D).

En la superficie externa de la agalla, y a nivel de la cámara larval, se observan las células epidérmicas con las paredes celulares marcadamente engrosadas y lignificadas. Esta epidermis lignificada carece de estomas y presenta taninos. En ambos folíolos de la agalla, entre la epidermis lignificada y la pared interna de la cámara larval se observan 1 2 estratos de esclereidas de forma oval, escasas células parenquimáticas y los haces vasculares colaterales reducidos y sin vaina (Figura 3 D-F). La anatomía isolateral del folíolo normal, con mesófilo diferenciado en parénquima en empalizada hacia ambas epidermis, células parenquimáticas redondeadas entre ambos y meatos, no se reconoce en los folíolos de la agalla. En los folíolos agallados 
Bol. Soc. Argent. Bot. 52 (3) 2017

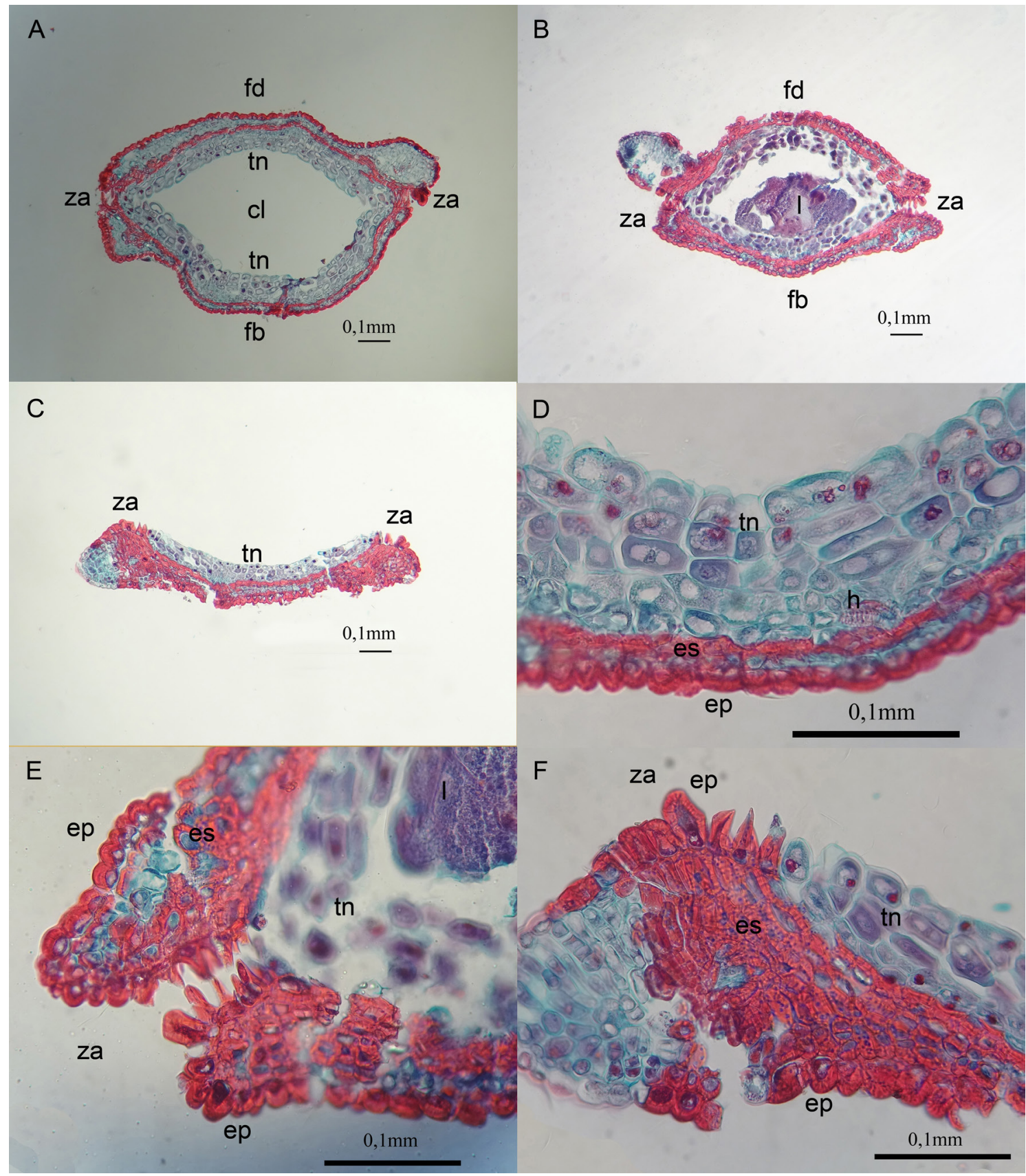

Fig. 3. Cortes transversales de agallas. A-B: Agalla con los folíolos acoplados, en B, con la larva en el interior de la cámara larval. C: Folíolo agallado. D: Detalle del tejido nutritivo que limita la cara interna de la cámara larval. E: Detalle de la zona de unión y encastre de los folíolos basal y distal. F: Detalle de la zona de unión en un folíolo agallado con las células epidérmicas modificadas en células nutritivas y en esclereidas con extremos aguzados y redondeados. cl: cámara larval, es: esclereidas, ep: esclereidas epidérmicas, fb: folíolo agallado basal (valva inferior de la agalla), fd: folíolo agallado distal (valva superior de la agalla), h: haz vascular, I: larva, tn: tejido nutritivo, za: zona de unión de los folíolos agallados. 
el tejido fotosintético no está diferenciado y es escaso, las células parenquimáticas con cloroplastos tienen forma celular redondeada y los meatos están reducidos. El espesor promedio de la lámina del folíolo agallado y a nivel de la cámara larval resultó igual a $0,11 \mathrm{~mm}(\mathrm{n}=6, \mathrm{ds}=0,01)$, aproximadamente la mitad del espesor del folíolo normal.

El corte microscópico de la protuberancia desarrollada en algunas agallas reveló la presencia de tejido parenquimático hiperplásico y compacto rodeado por una epidermis esclerenquimática (Figura 4). En la agalla senescente, el tejido parenquimático adquiere aspecto de súber con células muertas y frecuentemente con taninos contenidos en las células periféricas.

La venación en los folíolos agallados está reducida y simplificada. Las reducciones principalmente ocurren en el grosor de las venas y en el desarrollo de las venas secundarias. Las venas terciarias están poco o nada desarrolladas y las vénulas, en la mayoría de los folíolos agallados no se desarrollan (Figura 5).

\section{Discusión}

En el proceso de desarrollo de la agalla bivalva, se identifican las fases de desarrollo inducción, crecimiento y diferenciación, maduración y senescencia (Rohfritsch, 1992). En la fase de crecimiento y diferenciación ocurre hiperplasia e hipertrofia acorde a Rohfritsch (1992) y principalmente en el tejido nutritivo. En esta fase, las células epidérmicas son marcadamente modificadas y la disposición espacial de los folíolos se modifica para acoplarse perfectamente como dos valvas. Los folíolos se arquean y la agalla incrementa el tamaño fundamentalmente por aumentar el volumen de la cámara larval más que por aumentar la biomasa como menciona Rohfritsch (1992). En la fase de maduración la agalla bivalva está completamente formada y se reconocen anatómicamente los tejidos característicos de las agallas de cecidómidos (Rohfritsch, 1992; Stone \& Schönrogge, 2003; Oliveira \& Isaias; 2009). Un tejido nutritivo interno constituido por varias capas de células que tapiza la superficie interna de la cámara larval y está en contacto directo con la larva inductora. Un tejido esclerenquimático formado por braquiesclereidas que proveería soporte a la agalla y protección a la larva. Un tejido parenquimático compacto y escaso, con pocos cloroplastos y con meatos reducidos que posiblemente funcione como tejido de relleno con escasa actividad fotosintética, la cual se estaría limitada por la ausencia de estomas. La reducción de la vena principal y la desaparición

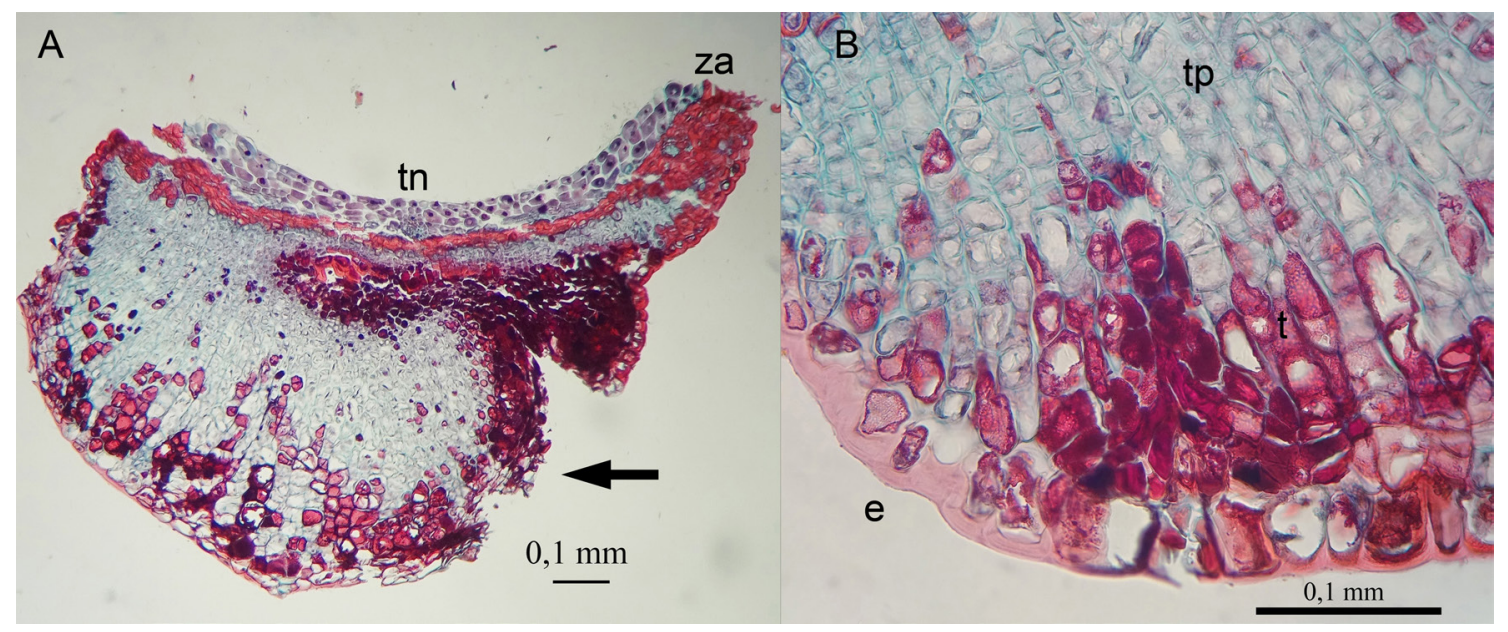

Fig. 4. Cortes transversales de un folíolo basal agallado con protuberancia. A. Folíolo agallado con protuberancia (flecha), B. Detalle del tejido parenquimático de la protuberancia. e: epidermis con cutícula, t: taninos, tn: tejido nutritivo, tp: tejido parenquimático, za: zona de unión. 

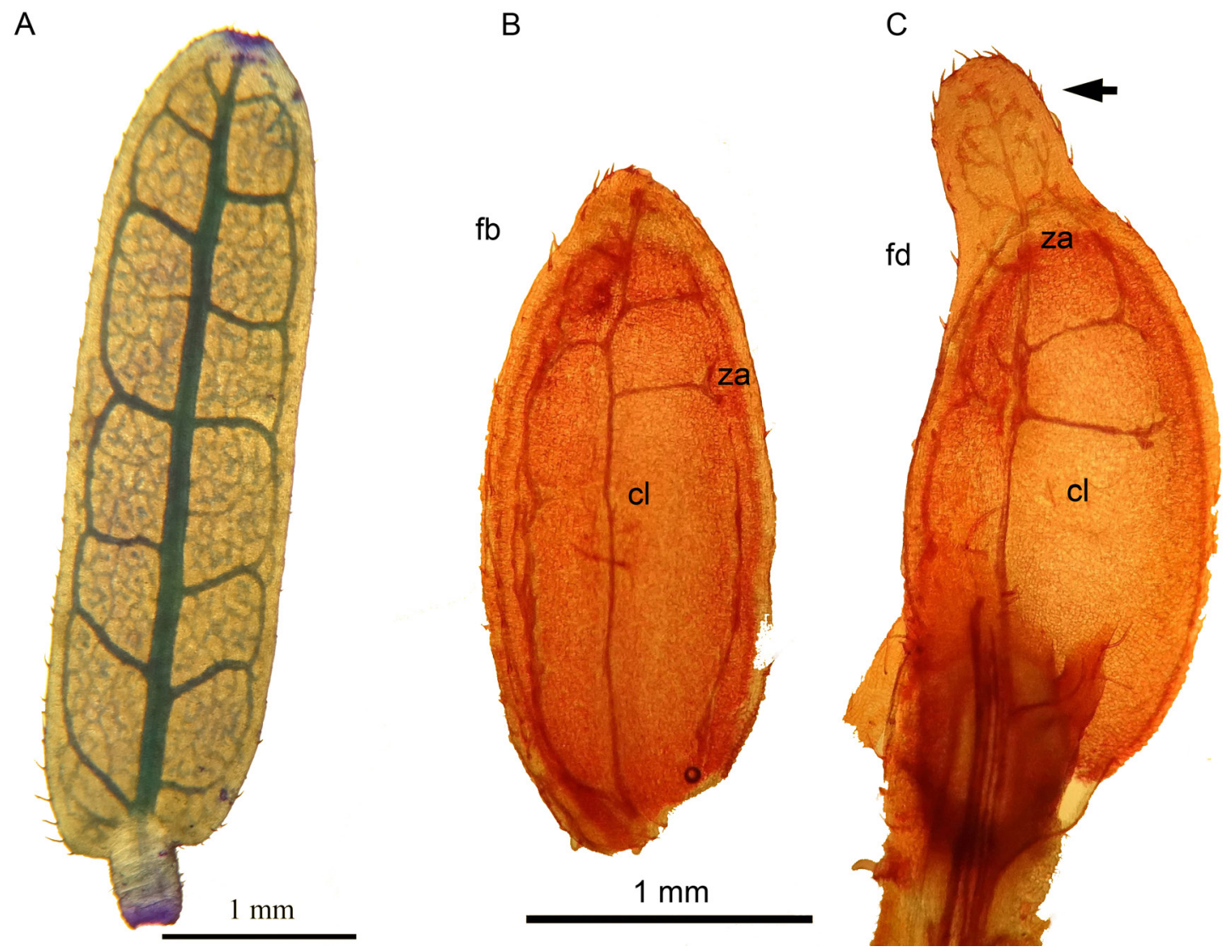

Fig. 5. Venación del folíolo normal y del agallado. A. Folíolo normal. B. Folíolos basal y distal de la agalla. cl: cámara larval, fb: folíolo basal, fd: folíolo distal, za: zona de acople de los folíolos. Flecha: parte apical de lámina del folíolo distal agallado que no ha sido incorporada en la formación de la cámara larval.

de la vaina del haz es acorde lo registrado en otras agallas foliares (Oliveira \& Isaias, 2009). En la fase de senescencia, ocurre la dehiscencia de la agalla. En las agallas foliares de cecidómidos, la absición y la dehiscencia de la agalla ocurren de diversas maneras siendo frecuente la dehiscencia mecánica (Dreger-Jaufret \& Shorthouse, 1992). Las agallas bivalvas estudiadas presentan dehiscencia mecánica, posiblemente la forma y la esclerificación de las células en la zona de contacto de las valvas, la deshidratación de los tejidos agallados y los movimientos de la pupa con el adulto pronto a emerger faciliten este tipo de dehiscencia.

En las agallas de cecidómidos, la epidermis puede sufrir alteraciones con diferentes grados de modificación (Rohfritsch, 1992, Isaias et al., 2014). En particular, en las agallas foliares se han descripto cambios en la forma de las células epidérmicas y aumento de divisiones celulares (Jayaraman, 1989; Formiga et al., 2011; Albert et al., 2013), formación de tricomas glandulares modificados (Kraus et al., 2003), modificaciones de la cutícula y lignificación de las células en el ostiolo de la agalla y formación del tejido nutritivo en contacto con la larva inductora (Oliveira \& Isaias, 2010). De manera similar a lo descripto en agallas formadas por el plegamiento de la lámina del folíolo (Oliveira \& Isaias, 2010), en la agalla bivalva estudiada, es 


\section{B. M. Corró Molas et al. - Agallas foliares en Prosopis caldenia}

la epidermis foliar de los dos folíolos involucrados el tejido que exhibe las modificaciones más profundas y diversas. La epidermis que dará origen al tejido nutritivo sufre hiperplasia e hipertrofia, la epidermis que tapiza la superficie exterior de la agalla se esclerifica y ambas epidermis carecen de estomas y tricomas. La epidermis esclerificada crea una cubierta que contribuiría a la protección de la larva y al sostén de las valvas. Por último, las modificaciones más peculiares ocurren en las células epidérmicas de la zona de unión de las valvas, las células se transforman en esclereidas con el extremo libre extendido y aguzado. Las modificaciones mencionadas facilitarían que las dos valvas se acoplen y encastren perfectamente de manera que la agalla permanezca cerrada y el inductor que se desarrolla en su interior, en ningún momento quede expuesto al ambiente. Asimismo, el encastre de las células epidérmicas facilitaría la dehiscencia mecánica de la agalla en el momento de la emergencia del adulto. Esto es diferente a lo que ocurre en las agallas formadas por el plegamiento de la lámina foliar inducidas por los cecidómidos Aspnhondylia riveae Mani y Aspnhondylia ipomoeae Felt, donde en ambos casos los adultos emergen por orificios de salida (Jayaraman, 1989).

El recubrimiento externo de la agalla, sin estomas y esclerificado podría facilitar el mantenimiento de las condiciones de humedad y temperatura adecuadas en la cámara larval. Mantener las condiciones hidrotermales adecuadas para el insecto inductor es uno de los factores asociados a la función protectora de las agallas (Price et al., 1987) y esto podría ser relevante en ambientes semiáridos donde habita $P$. caldenia.

Entre las agallas más complejas inducidas por cecidómidos se encuentran las que involucran la combinación de dos folíolos como las agallas cilindro-pistón en Acacia ferruginea DC. en la India (Harris, 2010). El morfotipo de agalla bivalva inducida por Rhopalomyia sp. en el caldén, por las características estructurales y anatómicas, podría constituir uno de los morfotipos de agallas de cecidómidos que exhiben mayor complejidad. Hasta el momento se han registrado agallas bivalvas en Prosopis alba (Griseb) y Acacia sp. en Argentina, (Gagné, 1994; Carabajal \& Fiorentino, 2006; Carabajal et al., 2009), en tres especies de Acacia Mill. en la India y Kenya (Gagné \& Marohasy,
1993; Harris, 2010) y en Parkia pendula (Willd.) Benth. ex Walp.en Brasil (Maia \& Fernandes, 2006).

Este trabajo aporta las primeras observaciones sobre las modificaciones de los tejidos foliares en agallas bivalvas de leguminosas neotropicales. La epidermis foliar es el tejido que experimenta el mayor grado de alteración en los folíolos agallados.

\section{Agradecimientos}

Quisiéramos expresar nuestro agradecimiento a las autoridades de la Dirección de Recursos Naturales del Ministerio de la Producción del Gobierno de La Pampa y del Vivero Forestal Provincial por los permisos de colecta y la colaboración prestada. Agradecemos al equipo de trabajo del Laboratorio de Morfología Vegetal de la Facultad de Agronomía y Veterinaria de la Universidad Nacional de Río Cuarto y especialmente al Técnico Hugo Quiróz. El presente trabajo fue realizado con financiamiento de la Facultad de Ciencias Exactas y Naturales, Universidad Nacional de La Pampa (Proyecto nro. 246) y de la Agencia Nacional de Promoción Científica y Tecnológica (PICT 2012-0617).

\section{Bibliografía}

ABRAHAMSON, W. G., G. MELIKA, R. SCRAFFORD \& G. CSÓKA. 1998. Gall -inducing insects provide insights into plant systematic relationships. Am. $J$. Bot. 85: 1159-1165.

ALBERT, S., S. RANA \& D. GANDHI. 2013. Anatomy and ontogenesis of foliar galls induced by Odinadiplosis odinae (Diptera: Cecidomyiidae) on Lannea coramandelica (Anacardiaceae). Acta Entomol. Serbica 18: 161-175.

ASH, A., B. ELLIS, L. J. HICKEY, K. JOHNSON, P. WILF \& S. WING. 1999. Manual of Leaf Architecture. Morphological description and categorization of dicotyledonous and net-veined monocotyledonous angiosperms. Smithsonian.

BOURG, A. \& P. HANSON. 2014. Host specificity of gall midges (Diptera: Cecidomyiidae) on ten species of Inga (Fabaceae). In: FERNANDES G. W. \& J. C. SANTOS (eds.), Neotropical Insect Galls, pp. 151162. Springer, London.

BRONNER, R. 1992. The role of nutritive cells in the nutrition of cynipids and cecidomyiids. In: SHORTHOUSE, J. D. \& O. ROHFRITSCH (eds.), 
Biology of Insect-induced Galls, pp. 118-140, Oxford University Press, Oxford.

CARABAJAL DE BELLUOMINI, M. V. \& D. C. FIORENTINO. 2006. Caracterización fitosanitaria de viveros de Prosopis alba (Griseb) en Santiago del Estero. Quebracho 13: 93-102.

CARABAJAL DE BELLUOMINI, M. V., L. CASTRESANA., V. SALIM \& A. NOTARIO. 2009. The diversity of galls and their occurrence in productive forest systems of Prosopis alba (Griseb) in Santiago del Estero, Argentine. Bol. Sanidad Vegetal de Plagas 35: 255-265.

CARNEIRO, M. A. A., C. S. A. BRANCO, C. E. D. BRAGA, E. D. ALMADA, M. B. M. COSTA, V. C. MAIA \& G. W. FERNANDES. 2009. Are gall midge species (Diptera, Cecidomyiidae) host-plant specialist? Rev. Bras. Entomol. 53: 365-378.

COOK, T. M. 1904. Galls and insects producing them. The Ohio Naturalist 4: 115-139.

CORRÓ MOLAS, B. M, J. J. MARTÍNEZ, L. CARBONELL SILLETTA, M. C. GALLIA \& G. L. ALFONSO. 2014. Modificaciones morfológicas inducidas por Tetradiplosis panghitruz Martínez (Diptera: Cecidomyiidae) en tallos de Prosopis caldenia Burkart (Fabaceae). Rev. Mus. Argentino Cienc. Nat. 16: 1-12.

D'AMBROGIO DE ARGÜESO. 1986. Manual de Técnicas en Histología Vegetal. Ed. Hemisferio Sur S. A., Buenos Aires, Argentina.

DAWKINS, R. 1982. The extended phenotype, Oxford University Press, New York.

DORCHIN, N., A. FREIDBERG \& R. ALONI. 2003. Morphogenesis of stem gall tissues induced by larvae of two cecidomyiid species (Diptera: Cecidomyiidae). Can. J. Bot. 80: 1141-1150.

DREGER-JAUFRET, F. \& J. D. SHORTHOUSE. 1992. Diversity of gall-inducing insects and their galls. In: SHORTHOUSE J. D. \& O. ROHFRITSCH (eds.), Biology of insect-induced galls, pp. 8-33. Oxford University Press, Oxford.

FERRAZ, F. F. F. \& R. F. MONTEIRO. 2003. Complex interactions envolving a gall midge Myrciamyia maricaensis Maia (Diptera, Cecidomyiidae), phytophagous modifiers and parasitoids. Rev. Bras. Zool. 20: 433-437.

FORMIGA, A. T., G. L. G. SOARES \& R. M. S. ISAIAS. 2011. Response of the host plant tissues to gall induction in Aspidosperma sprunceanum Müell. Arg. (Apocynaceae). Am. J. Plant Sci. 2: $823-834$.

GAGNÉ, R. J. 1994. The gall midges of the Neotropical Region. Cornell University Press.

GAGNÉ, R. \& J. MAROHASY. 1993. The gall midges (Diptera: Cecidomyiidae) of Acacia spp. (Mimosaceae) in Kenya. Insecta Mundi 7: 77-124.
HARRIS, M. K. 2010. Contarinia manii sp. n. (Diptera, Cecidomyiidae): inducer of a remarkable gall on Acacia ferruginea in southern India. Zootaxa 2423: 63-68.

HICKEY, L. J. 1974. Clasificación de la arquitectura de las hojas de Dicotiledóneas. Bol. Soc. Arg. Bot. 16: $1-26$.

ISAIAS, R. M. S., D. C. OLIVEIRA, R. G. S. CARNEIRO \& J. E. KRAUS. 2014. Developmental anatomy of galls in the Neotropics: arthropods stimuli versus host plant constraints. In: FERNANDES G. W. \& J. C. SANTOS (eds.), Neotropical Insect Galls, pp. 15-34. Springer, London.

JAYARAMAN, P. 1989. Ontogenetic studies on some leaf-fold galls. Proc. Indian Natn. Sci. Acad. 55: 57-62.

KIEFFER, J. J. \& P. JÖRGENSEN. 1910. Gallen und Gallentier aus Argentinien. Zentralbl. Bakteriol., Parasitenkd. Infektionskr. 27: 362-442.

KRAUS, J. E. 1997. Respostas morfogenéticas de plantas a insetos indutores de galhas. In: ARAÚJO, M. C. P., G. P. COELHO \& L. MEDEIROS (org.), Interações ecológicas \& biodiversidade, pp. 59-751. Ijuí, RS, UNIJUI.

KRAUS, J. E., R. M. S. ISAIAS, C. VECCHI \& G. W. FERNANDES. 2003. Structure of insect galls on two sympatric subspecies of Chrysothamnus nauseosus (Pall. Ex Pursh) Britton (Asteraceae). Bol. Bot. Univ. Sao Paulo 21: 251-263.

MAIA, V. C. 2012. ColeOpterous galls from the Neotropical Region. Papéis Avulsos de Zool. 52: 175-184.

MAIA, V. C. 2014. Cecidomyiidae. In: ROIG JUÑENT, S., L. E. CLAPS \& J. MORRONE (eds.), Biodiversidad de artrópodos argentinos, vol. 4, pp. 339-357. Ed. INSUE-UNT, San Miguel de Tucumán, Argentina.

MAIA, V. C. \& G. W. FERNADES. 2006. A new genus and species of gall midge (Diptera, Cecidomyiidae) associated with Parkia pendula (Fabaceae, Mimosoidea). Rev. Bras. Entomo. 50: 1-5.

MARINI-FILHO, O. J. \& G. W. FERNANDES. 2012. Stem galls drain nutrients and decrease shoot perfomance in Diplusodon orbicularis (Lythraceae). Arthropod Plant Interact. 6: 121-128.

MARTÍNEZ, J. J. 2009. Diversidad de Doryctinae (Insecta: Hymenoptera: Braconidae) de la Argentina, con énfasis en las formas gallícolas. Tesis de Doctorado de la Universidad Nacional de Buenos Aires.

MARTÍNEZ, J. J. \& B. M. CORRÓ MOLAS. 2016. Las agallas inducidas por ácaros e insectos en Prosopis caldenia Burkart (Fabaceae). p. 40, Libro de Resúmenes XII Jornadas Pampeanas de Ciencias Naturales, Santa Rosa, La Pampa, Argentina. 


\section{B. M. Corró Molas et al. - Agallas foliares en Prosopis caldenia}

MARTÍNEZ, J. J., B. M. CORRÓ MOLAS \& G. L. ALFONSO. 2013. New species of Tetradiplosis (Diptera: Cecidomyiidae) inducing galls on Prosopis caldenia (Fabaceae) in Argentina. Zootaxa 3702: 587-596.

MÉNDES DE SÁ, C. E., F. A. O. SILVEIRA, J. C. SANTOS, R.M.D.S.ISAIAS \& G. W.FERNANDES. 2009. Anatomical and developmental aspects of leaf galls induced by Schizomyia macropillata Maia (Diptera: Cecidomyiidae) on Bauhinia brevipes Vogel (Fabaceae). Rev. Bras. Bot. 32: 319-327.

OLIVEIRA, D. C. \& R. M. S. ISAIAS. 2009. Influence of leaflet age in anatomy and possible adaptive values of the midrib gall of Copaifera langsdorffii (Fabaceae: Caesalpinioideae). Rev. Biol. Trop. 57: 293-302.

OLIVEIRA, D. C. \& R. M. S. ISAIAS. 2010. Redifferentiation of leaflet tissues during midrib gall development in Copaifera langsdorffii (Fabaceae). S. Afr. J. Bot. 76: 239-248.

OLIVEIRA, D. C., T. A. MAGALHÃES, R. G. S. CARNEIRO, M. N. ALVIM \& R. M. S. ISAIAS. 2010. Do Cecidomyiidae galls of Aspidosperma spruceanum (Apocynaceae) fit the pre-established cytological and histochemical patterns? Protoplasma 242: 81-93.
PRICE, P. W., G. W. FERNANDES \& G. L. WARING. 1987. Adaptative nature of insect galls. Environ. Entomol. 16: 15-24.

RAMAN, A. 2007. Insect-induced plant galls of India: unresolved questions. Curr. Sci. 92: 748-757.

ROHFRITSCH, O. 1992. Patterns in gall development. In: SHORTHOUSE J. D. \& O. ROHFRITSCH (eds.), Biology of insect-induced galls, pp. 60-86, Oxford University Press, Oxford.

ROHFRITSCH, O. 1999. A so called "rudimentary gall" induced by the gall midge Physemocecis hartigi on leaves of Tilia intermedia. Can. J. Bot. 77: 460-470.

STONE, G. N. \& J. M. COOK. 1998. Evolution of gall structure in oak gall wasps. Proc. R. Soc. Lond. B 265: 979-988.

STONE, N. G. \& K. SCHÖNROGGE. 2003. The adaptative significance of insect gall morphology. Trends Ecol. Evol. 18: 512-521.

Recibido el 26 de septiembre de 2016, aceptado el 26 de enero de 2017. 
